\title{
Research on the Design Expression of Genius Loci in Memorial Landscape Spaces
}

\author{
Xiaomin Chen \\ College of Landscape Architecture \\ Sichuan Agricultural University \\ Chengdu, China 611130 \\ Jun Chen \\ College of Landscape Architecture \\ Sichuan Agricultural University \\ Chengdu, China 611130 \\ Panpan Cao \\ College of Landscape Architecture \\ Sichuan Agricultural University \\ Chengdu, China 611130
}

\author{
Bei Wang \\ College of Landscape Architecture \\ Sichuan Agricultural University \\ Chengdu, China 611130 \\ Miao Xiong \\ College of Landscape Architecture \\ Sichuan Agricultural University \\ Chengdu, China 611130 \\ Xiaofang $\mathrm{Yu}^{*}$ \\ College of Landscape Architecture \\ Sichuan Agricultural University \\ Chengdu, China 611130 \\ *Corresponding Author
}

\begin{abstract}
- genius loci is a sense of identity and belonging that people hold to a place, this feeling will potentially influence what the people think and do. Memorial landscape spaces are public spaces that carry human history, culture, memory and emotion, whose spiritual functions are far beyond the material functions. The design of memorial landscape spaces shall show more than whom to commemorate, more importantly, it shall be focused on the psychological needs memorial subjects so that the people get a sense of place and better create a space atmosphere. This article analyzes the characteristics of the genius loci and the related design-related factors on the basis of memorial landscape space, hoping to find the genius loci that the memorial spaces should have and express it better in the design language.
\end{abstract}

Keywords-memorial landscape space; place; genius loci

\section{INTRODUCTION}

Genius loci is an atmosphere, a sense of identity and belonging that people hold to a place, this feeling will potentially influence what the people think and do. The places which have no genius loci will make the people feel strange, out of energy and vitality due to the lack of culture and emotion. Memorial landscape spaces are public spaces that carry human history, culture, memory and emotion, whose spiritual functions are far beyond the material functions. The design of memorial landscape spaces shall show more than whom to commemorate, more importantly, it shall be focused on the spiritual needs memorial subjects so that the people get a sense of belonging and better create a space atmosphere and express the genius loci. The genius loci is critical for the tenet of memorial landscape design, and whether the genius lock is rationally expressed or not has often become a standard to weigh the design success of a memorial landscape. Therefore, this article analyzes the characteristics of the genius lock and related design factors, hoping to find the genius loci that the memorial spaces should have and express it better in the design language and creating a memorial landscape space with unique atmosphere.

\section{Connotation OF GeniUs LocI}

Space is not the same as a place, only when the space used by human for social purposes can it be called place. Norberg Schultz turned a "space" into a "place" to achieve the organic connection between human and architecture [1]. The space that a landscape can express and contain is often considered to be "all over the earth and under the sky". Thus, the term "place" does not just refer to the interior of a building, but also contains a vast space in nature. And it has a strong toughness, which can be expanded to accommodate other things. Whether it is a place formed naturally or created and designed artificially both are inseparable and supporting each other. For example, the trend of a mountain can determine the direction of a house, and the veins of a river will affect the layout and development of a city "Fig. 1". 


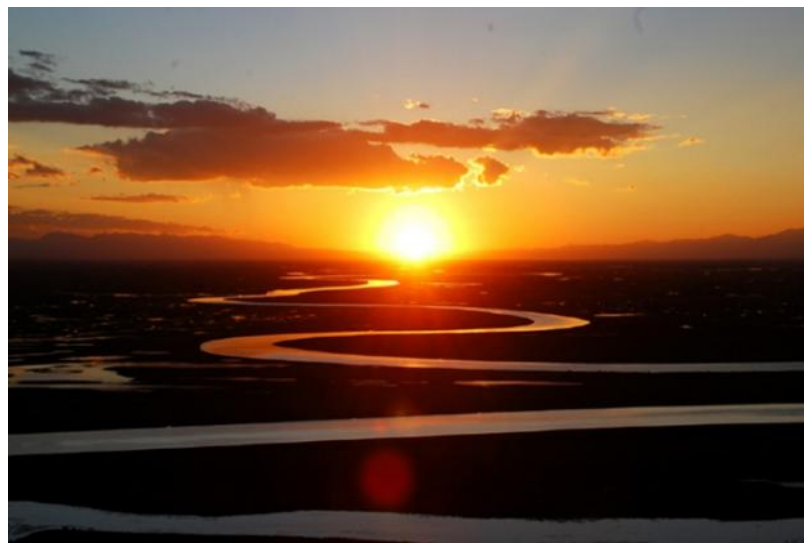

Fig. 1. Landscape of Yellow River.

The space is focused on the relations between threedimensional figures, and the place is mostly discussing a sense of life. The place is where we experience the goals and focus of meaningful events that exist, and also a starting point for us to adapt to and occupy the environment [2]. Norbert Schultz, a famous Norwegian urban architect raised the concept "Genius loci" in 1979 [3]. He mentioned that human began to realize the existence of themselves in the Roman era, and human and places had an internal spirit to express, which will accompany with them all the life, the spirit is just genius loci. The theory of architectural phenomenology written by Norberg-Schultz indicated that a place is composed of many phenomena, including flowers, grass, trees, blue sky, white clouds, rivers and mountains, day and night, seasons, creatures, etc., which are a whole that consist of natures, shapes, senses and colors specific things. In the studies of memorial genius loci, we have found that abundant land stated in "abundant land and outstanding people" that are said frequently shows similar connotations. The growing flows, grass and trees, gray bricks and white tilts, winding mountains, unceasing rains and snows as well as sun and moon and stars, all are the projection of genius loci in real life, and the collection of such things has formed an environmental nature, that is nature of a place. The genius loci is to make the nature of a place meet the natural environment, folk customs and religious beliefs where local people depend on. Just like the Greeks will select carefully different places to build temples, because they think that different places have different dispositions, meeting different gods.

\section{GeniUs Loci Of MEMORIAL LANDSCAPE SPACES}

Memory refers to a mood of nostalgia and recall that people hold to what have passed or been lost. Memorial landscape space has memorial characteristics for people to memorize, causing a feeling to think and recall. Nowadays, the definition of space made by a famous Japanese architect Luranraison, who thinks that a space consists of relations between a thing and the people who feel it, external space is an external environment that human creates for some purposes, which has more significances than the nature [4]. If the existence of a space lies in the perception of things, then the memorial space exists because human has yarning perception for things with memorial significance such as structures, buildings and so on. For example, in villages, the village entrance is a space with memorial nature. Generally there will be trees, wells and open places, where villagers often hold meeting, have parties or celebration. And villagers will pass by the place when entering or leaving the villages, as such for a long time, it will has become a symbol of the village, when recalling the village, villagers will first think of the entrance of the village. Similarly, when recalling childhood, we will remember where we play in childhood, when recalling the green campus life, we will remember blackboards in classrooms; when recalling mothers, we will think of the kitchens where they were busy... all of the memorial moods are brought to us by spaces that carry events.

\section{A. Characteristics of Genius Loci}

In the late 20th century, Norberg - Schultz systematically put forward three main characteristics of the genius loci: sense of direction, sense of identity and sense of belonging [5] . The sense of direction means that human in a space can judge where they are and then grasp the relations between he and the environment, getting a sense of security; the sense of identity means that human, through understating the culture and feelings where the survive, form a mood of identifying the space and events, getting the sense of belonging in the space.

\section{1) Direction of places}

The direction of a place refers to an ability that a person holds in a place that can identify the direction, clearly understanding the relations between him and the place so as to get a sense of direction and sense of internal security. Amos Rapport, an architectural theorist, thought that people respond to the environment according to the significance they get from the environment, and raised in his works the Significance of Building the Environment that if the environment design is seen as a process of information coding to some degree, then the users can be seen as decoding to it [6]. Those who are kept in spaces to sense directions have to depend on elements such as roads, borders, region, nodes, and marks and so on [7]. Wandering ways at home town, walls of the residential areas, green grass at the football field, corridors at the courtyard, and sculptures in the middle of square, all of these landscape elements that the people in spaces can feel the sense of belonging. Therefore, when creating a memorial landscape space, we need to grasp the first point that is the sense of the direction of the place, establishing a structural system with clear veins and orders so as to avoid the moods of strangeness and loss due to the lack of sense of directors. Ancient architectural groups in China were focused on systems and orders, for example, the shafts of building groups in ancient imperial city that is the Forbidden City are clear, specific sense of directions, as well as clear in size, position and rhythm changes, which reflected spiritually traditional Confucian culture "Fig. 2". 


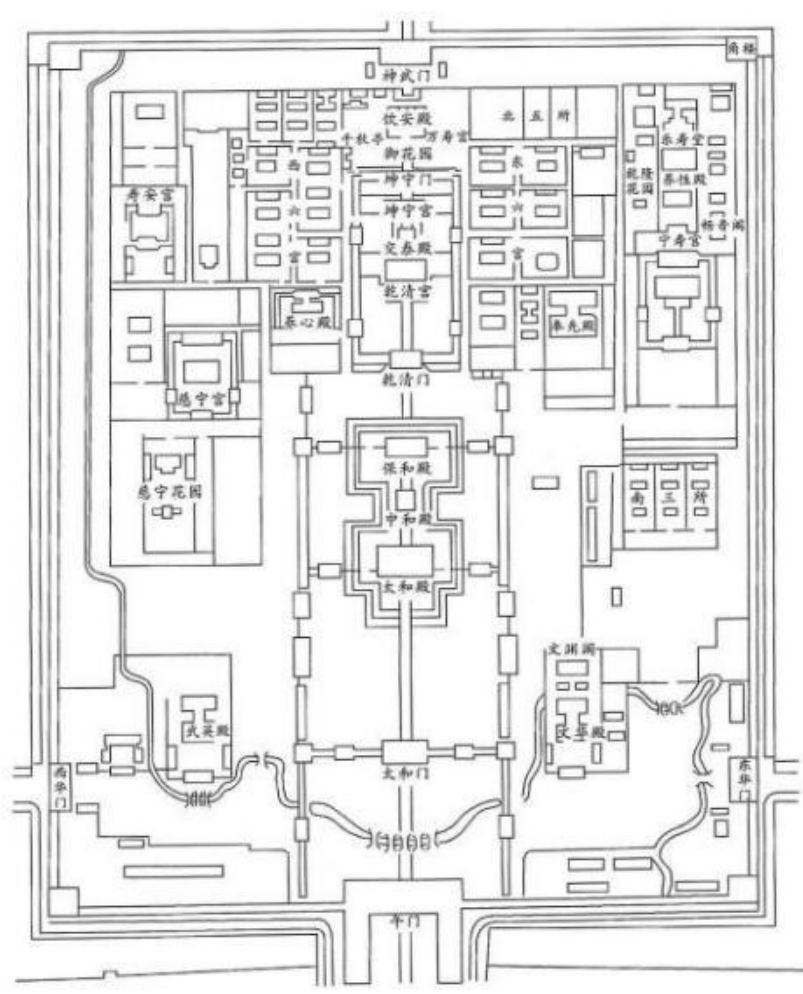

Fig. 2. The Palace Museum.

\section{2) Sense of place identity}

The sense of identity is a feeling that human holds to a place through gradual adaptation, usually accompanied by specific environmental nature. In our minds, the memories of the hometown are generally carrying places where we played with friends and walked with families, the public spaces open in cities, but not tall, cold buildings. Streets, lanes, squares, parks, riverside and even house roofs and small courtyard dam in front of gate, all of the open spaces where we live have formed the image and perception that we hold to the city, which are our identity to the living environment [8].

The sense of place identity is a special emotional expression and sublimation of space experience, which can be achieved through the emotional design. For landscape designers, the focus of emotional design is how to plan the relations between human emotions and genius loci, more than how to design the landscape environment. We are required to find a balance point to guide the people's emotions to start from beginning, into the climax and return to calm, so that the feelings originally existing in hearts can be dug up. In order to feel the genius loci of memorial spaces, the feelings existing differ with mountain, lakes, trees and buildings or bridges, it is out of material elements, like spirit and soul, generally found in various elements. In the memorial landscape spaces, the emotional design on how to express emotions is a design mode which takes emotion as an important design factor and other as supports. When conducting the emotional design of memorial landscape spaces, we should change the mentalities we hold to the past such as sadness and escape, help the people express feelings and change it into a feeling with richer contents, such as enthusiasm to life, focus to realize the value of their own, so as to help the people better interpret the positive meanings of living and life and cherish the living and life they hold now.

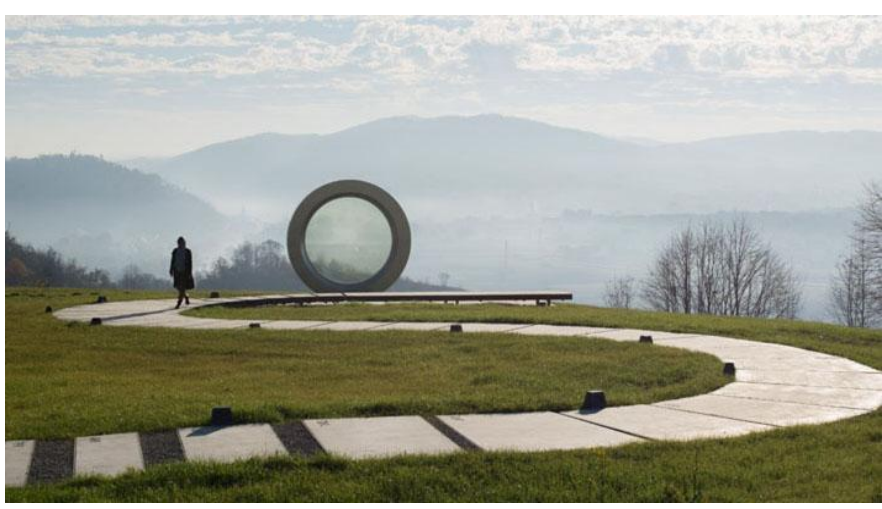

Fig. 3. The Gordan Lederer Monument.

In memory of HRT photographers and press photographers sacrificed in Croatia war in 1991, NFO team and landscape sculptor Petar Barisic jointly design the Gordan Lederer Monument "Fig. 3". Located in Cukur hill, the monument called "the broken landscape" has special emotional design. Its appearance simulates camera lens and it has a hole as if the sniper's bullet passes through in the center. There is a winding path in the place with the road paved by concrete slab and black steel frames as the intervals. People walk toward the monument through the footpath like film. The footpath represents Lederle's life formed by memorable stages. The monument takes breath-taking Una valley as the background. When people see the landscape of valley through the window, they will experience the memory about Lederle's death and have place emotions and identity. Each element in this place has representative significance. Passing through it makes people experience life and death of Lederle and reminds people of the gray war times.

\section{3) Sense of place belonging}

Sense of belonging is part of cultural psychology, referring to identity of individuals or collectives for things, phenomenon and space, the close degree related to things or phenomenon and the result that people involve affection in some place. [9] With sense of belonging, we will treat the place like our "home", in which we have sense of safety. Specifically, sense of belonging mainly refers to people's feeling of belonging to some place on the basis of sense of direction and establishing environmental identity. Many memorial landscape spaces emphasize sense of direction but attach inadequate importance to sense of identity and sense of belonging. In shaping memorial landscape space, more attentions must be paid to people's sense of identity and sense of belonging towards memorial subjects. Although people don't have personal experience, they can have profound reflection on memorial subjects. 

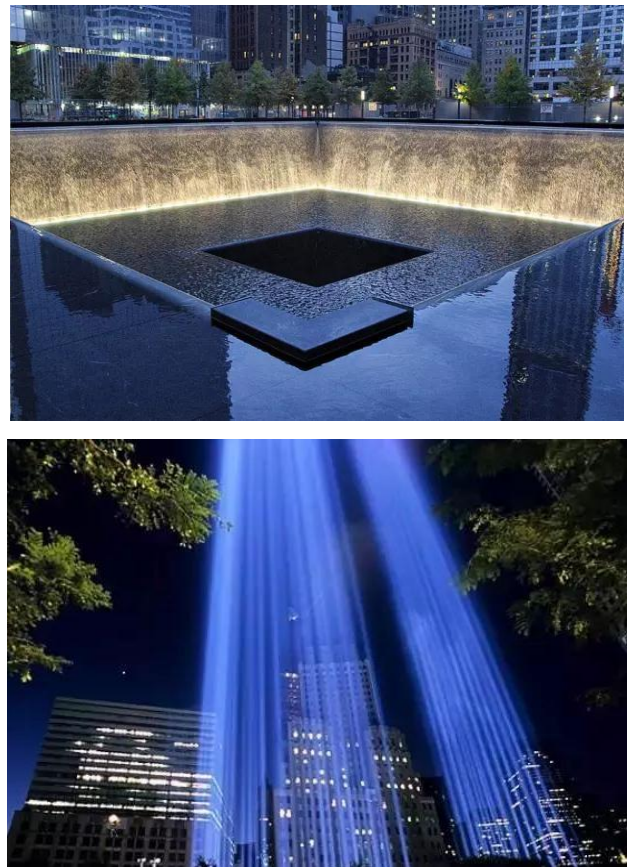

Fig. 4. 9-11 Memorial square.

In the design of American 9-11 Memorial Square, designers design two subsided waterfall plunge space on the original place of Twin Towers with the concept of "absence of inverted image", representing the existence and inverted image of the two buildings and letting people have the feeling of "loss". On the metal barrier of plunge pool, the names of more than 3,000 victims are engraved in hollowed-out way. The continuous water flow makes people feel the elapse of time and life and lets them more deeply think the meaning of life when they cherish the memory of victims. When night falls, two bright lasers soar to the deep night sky, like the rebirth of Twin Towers, comforting the spirit of the deceased and people's heart "Fig. 4".

\section{B. Design Elements of Genius Loci in Memorial Landscape}

Establishment and expression of Genius loci is influenced by many aspects, including environment, time and context. In space design of memorial landscape, it's important to grasp influence elements of space spirit, convey spiritual significance contained in memorial landscape space to people to create appealing memorial place with sense of belonging and guide people to comprehend the connotation and memorial information and feel its spirit and atmosphere.

\section{1) Environmental elements in memorial place}

In the book of Existence, Space and Architecture, NorbergSchulz proposes the concept of "Existence Space". "Existence space refers to relatively stable perceptual mapping system, namely the image of environment." [10] He observes space forms are not simple composition game but contain profound meaning. Elements such as light and wind, rain and snow, green plants, blue sky and sea are taken as background of scene to let people have peaceful, relaxed and open feeling and more associations, and form poetic imagery beauty. We can reasonably use environmental image and let places tell stories about themselves and people.

In the only cemetery project of Tadao Ando in his career, he takes water, plant and sunshine as three main elements in his design "Fig. 5". The subject of cemetery is a huge water pond, the half of which is underground as a part of the world. Like a mirror, it reflects the surrounding beautiful sceneries; the other end of water body forms cascading waterfall with height of 12 meters and width of 90 meters, creating the curtain formed by numberless water drops. Water symbolizes source of life. Water pond is the container to purify people's life. People who come here will first see the water pond and reach the spiritual world of the deceased through the aisle above the water pond. Tadao Ando chooses sakura to surround the water area because the life span of it is similar to human, about 80 years. The beautiful sakuras aren't planted by builders but family members of the deceased. When people linger and see the sakuras grow as time goes on, they as if see their relatives live happily in another world. It will greatly comfort people's heart. In the Cemetery of Water, Tadao Ando uses environmental elements to shape the spirit of place and creates a purified spiritual world to purify people's soul.
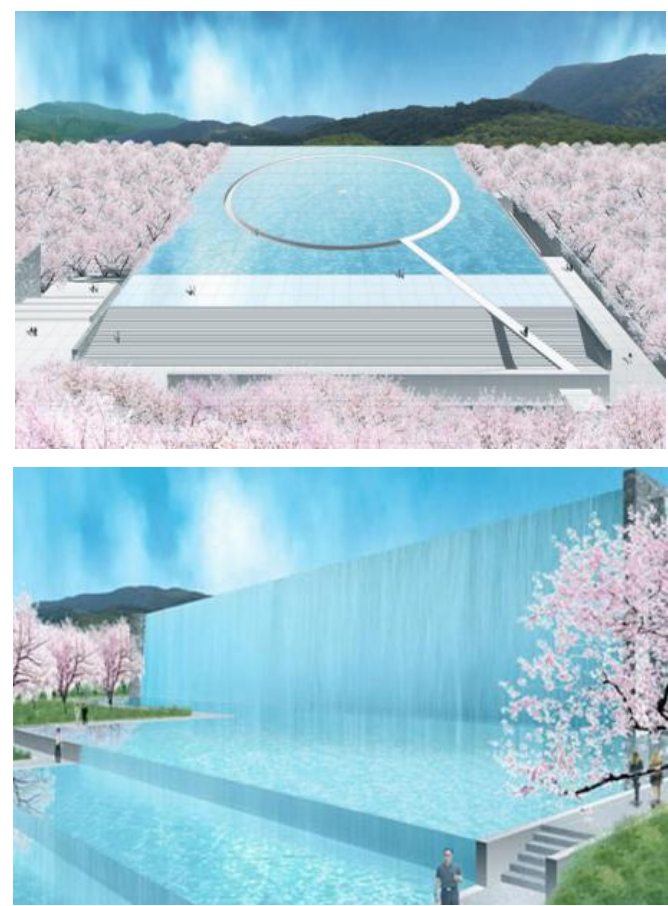

Fig. 5. Tadao Ando'Cemetery of Water.

\section{2) Time element of memorial place}

Chen Congzhou, the master of landscape architecture, writes in Discussion on Gardens that "gardens have in-motion viewing and in-position viewing". Time passes in relatively fixed space. Gardens combine time and space. The flow and changes of time make landscape architecture more affluent. The perception and experience integrates subject, space and time. Understanding the influence of time element in memorial space has important significance on completely understanding place spirit. 
In urban region, time contributes to lush and vigorous plants and improves landscape, instead of the distressing "loss". Time changes people's attitude toward place. As creator of landscape, it exists everywhere. People obviously feel time in memorial landscape space. Not representation but effect is important in landscape. Perception is prior to feelings. People will think about what they feel, what they think and what makes them curious. It could be blue streak, the growth of flowers, the sceneries of sun and moon, wind and rain. Attentions are paid to "Poetic imagery beauty" in Chinese classical garden. It forms by elements, space, connotation and perception. When feeling whole-heartedly, people will enter the "long" space and time and completely forget themselves and immerse in the aesthetic atmosphere. Our life is recorded in the space where we live, in reality, it's recorded by time. The growth of plants, stone steps with long history and the shadow of sunshine on our body remind us the elapse of time.

With delicate design, some landscape spaces will "compress" time while some will "prolong" time. With the sense of tininess in the natural world, we can feel "absolute time", and feel "relative time" through sense of rhythm in movement experience space. Time element of place is set through guiding the attention of experiencers. For example, in the design of Zichen Temple of Xi'an Daming Palace National Heritage Park, designers hope to present the dynamic and stable image "Fig. 6". If it keeps shifting like the clouds, the memory will be absent; while specific architecture will block people's thought and imagination. Therefore, after prediction and estimation according to archaeological and historical materials, designers build boundary framework of the original Daming Palace and plant trees in the center, and trim contour of these trees to supplement the appearance of Daming Palace. As time goes by, we can see the brand new life of Daming Palace at all seasons and how to use time to build the everlasting palace in long history. In spring, the trees sprout and gradually grow. Daming Palace revives like a baby, tender and lovely and full of vitality; in summer, the lush branches and leaves grow and sway with the wind and cover the contour of the building. Daming Palace with explicit contour is submerged in sunshine and forest and resembles the disappearing and distant history; in autumn, diversified tress present varied colors and layers with swirling fallen leaves, as if Daming Palace dances in autumn wind, bleak and lonesome; in winter, deadwood appears and highlights Daming Palace, which resembles an old man, grand, solemn and silent as well as sad and beautiful. With the passage of time, the appearance of Daming Palace runs in cycle... In history, the image of Daming Palace is insubstantial, but "the Palace in Time" opens people's memory and imagination.

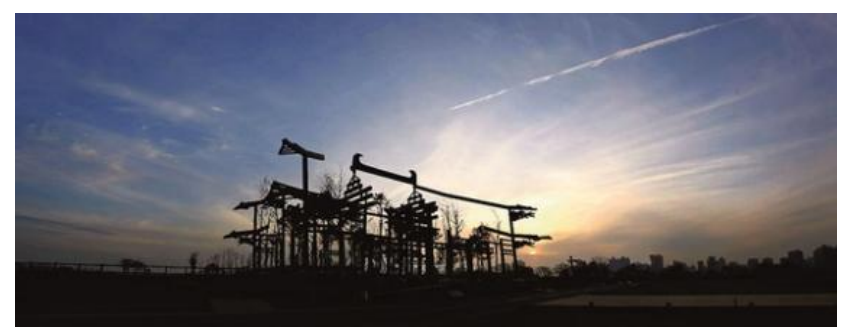

Fig. 6. The palace in the passage of time-Zichen Temple of Xi'an Daming Palace National Heritage Park.
Memorial landscape space realizes the dialogue between the living and the deceased and enables the living to perceive life and think about the future. Time is fleeting and only spirit is eternal. One of the primary missions in design of contemporary memorial landscape is to convey the concept of "eternity in time". It's effective means to enrich place spirit through exploring design of memorial landscape space from time dimension and researching the influences of the past, the present and the future.

\section{3) Context element in memorial space}

No matter how fundamental is a design, it must connect with the previous place. Even experienced designers often rack their brains about "the ethos of place". [11] Except for emotion and time, the continuity has another important element, namely context. The influence of culture on memorial landscape space is not second to the effect of motion on it. Significance of place forms place spirit. The formation background of significance and measurement criteria closely relate to social culture. [12] Cultural characteristics are soul of a city. The spirit of historical context is the comprehensive expression of nationality and regional culture. In memorial landscape, each memorial subject has rich history that has extraordinary significance and values on people. The bygone and the varied history constitute the history of a city.

The inheritance of spirit of historical context in construction of memorial landscape space makes space pattern, dimension, color and material of the new environment express the development history of city. Cultural atmosphere and characteristics strengthen people's space cognition and sense of belonging, in order to protect the culture of memorial landscape space and promote the development of it. Continuing context of memorial landscape space is to continue urban context and pass historical and cultural information as well as place spirit of city.

Located in the center of Washington, D.C., Vietnam Veterans Memorial refers to black granite wall like two mirrors under horizon line "Fig. 7". Names of soldiers sacrificed in Vietnam War are engraved on the monument in time order. It resembles wound cut on the ground, extending to both ends infinitely and finally disappearing on the ground. Both ends of the monument face toward Lincoln Memorial and Washington Monument respectively. Towering and dignified under the sky, Vietnam Veterans Memorial creeps and expands on the earth, continuous and sad. Two black granite walls form time circle of this war. The start time of Vietnam War in 1959 and the end time in 1973 are recorded at the junction of walls where the time circle of war ends. Lin Ying says, "The living and the deceased will meet again in junction of the sunny world and the dark and silent world". People bring miss and tears and take away deep thought and sorrow. 


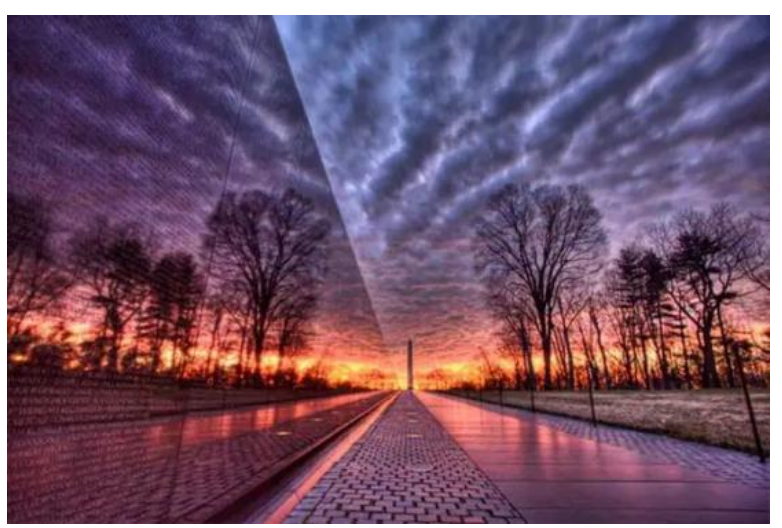

Fig. 7. The Monument of Vietnam war.

\section{CONCLUSION}

As urban special public space, memorial landscape space exists for the living. Designers design according to the emotions of the living in cherishing the memory of the deceased to express place spirit and impress visitors deeply. The place spirit of memorial landscape space realizes the communication between the living and the deceased and the dialogue between "the living" and "the living". NorbergSchultz uses "place spirit" to express underlying characteristics such as atmosphere of "place". The characteristics are unique and inherent charm of place. Just like a philosophy proposition in ancient Greek describes, "Place has its own strength". Pay attention to and correctly express the strength, so that landscape designers can write like an angel in creating space.

\section{REFERENCES}

[1] Relph E C. Place and placelessness[J]. Geographical Review, 1978, 68(1):116.

[2] Norberg-Schulz, Christian. Meaning in Western architecture[M]. Praeger, 1975.

[3] Li Yanshu. Place Spirit of Road-Taking Chaosheng Road in Yubeng Village as an Example [J], Urban Geography, 2015(18)

[4] [Japan]Ashihara Yoshinobu, translated by Yin Peitong. Exterior Space Design [M], Beijing: China Building Industry Press, 1985

[5] Yu Feifei, Li Guiyuan. Discussion on Landscape Space on College Campus Based on Genius loci[J], Planners, 2010, 26(12): 97-101

[6] Rapoport A. The Meaning of the Built Environment[J]. Man, 1982(10): 176.

[7] Wang Yi. Discussion on the Expression of Place Spirit in Urban Landscape Design [D], Shenyang Jianzhu University, 2011

[8] Lynch K. The Image of the City[M]. MIT Press, 1960.

[9] Li Wei. Discussion on Cultivation of Sense of Community Belonging [J], Dongyue Tribune, 2002, 23(2): 46-48

[10] Norberg-Schulz C. Existence, Space and Architecture[M]. 1971.

[11] Kevin Lynch, Gary Hack, Overall Design [M], China Architecture and Building Press, 2006

[12] Guo Suming, Zhou Haoming. Return of Place Spirit of Urban Commercial Pedestrian Street [J], Mountain Flowers, 2003 (5): 112-116. 